\title{
Dedicated SAR interferometric analysis to detect subtle deformation in evaporite areas around Zaragoza, NE Spain
}

\author{
CARMEN CASTANEDA* $†$, NADINE POURTHIÉ§ and JEAN-CLAUDE \\ SOUYRIS $\S$
}

$\uparrow$ Soil and Irrigation Department (associated with EEAD-CSIC), Agrifood Research and Technology Centre of Aragon (C.I.T.A.), 930 av. Montañana, 50059, Zaragoza, Spain

†Laboratoire Dynamique Terrestre et Planetaire (UMR 5562)-Université de ToulouseC.N.R.S., 14 v. E. Belin, 31400, Toulouse, France

$\S$ Centre National Etudes Spatiales (C.N.E.S.), 18 av. E. Belin, 31401 Toulouse, France

\begin{abstract}
A high density of local natural and human-induced ground deformation structures resulting from the presence of evaporites occur extensively around Zaragoza (NE Spain), posing risks to infrastructures, buildings and agriculture. We studied the potential of a series of interferograms constructed from 29 ERS -1/2 images to detect different types of ground deformation related to evaporite dissolution, landslides, and mining subsidence. We examined the factors involved in the usefulness and quality of interferograms, especially in relation to coherence and atmospheric circumstances. Favourable conditions were found in desert or developed areas, while agricultural practises caused decorrelation in most sinkholeprone areas. Results are consistent with previous geomorphological data and indicate that different natural and human-induced deformation phenomena can be detected in a time lag less than 5 years in evaporite areas. Advanced interferometric techniques based on time series of SAR images are needed for precise measurement and monitoring purposes.
\end{abstract}

\section{Introduction}

In the centre of the Ebro Basin, NE Spain, evaporite dissolution and subsidence are active processes that continuously modify the landscape through the development of alluvial dolines in a wide range of sizes which affect the dynamics of fluvial systems (Benito et al. 2000). In the environs of the city of Zaragoza, karstic subsidence causes considerable damage to linear infrastructures, buildings, and agriculture, resulting in substantial economic losses (Gutiérrez-Santolalla et al. 2005). Sinkhole size ranges from $1.5 \mathrm{~m}$ to $850 \mathrm{~m}$ in length, and their density varies from 140 to 600 sinkholes $/ \mathrm{km}^{2}$, according to Gutiérrez et al. (2007). Moreover, active slope movements affect the gypsum outcrops, especially along the linear escarpment upstream of Zaragoza city where evaporite dissolution is favoured by the river channel (Gutiérrez et al. 1994). To produce predictive maps and reduce sinkhole and landslide risk, the delimitation of active deformation areas is required. However, anthropogenic activities and natural

${ }^{*}$ Corresponding author. Current email address: ccastaneda@eead.csic.es 
processes may obliterate the geomorphic expression of the sinkholes and deformation structures.

Synthetic Aperture Radar Interferometry (InSAR) is a powerful geodetic technique which makes possible the estimation of subtle topographic changes (Massonet et al. 1993) over large areas. Under the appropriate conditions it is possible to measure changes in topography and earth surface deformation with centimetre and millimetre accuracy (Massonnet and Feigl 1998). Conventional InSAR has been found to be useful for environmental applications related to slow ground deformation caused by mining (Raucoules et al. 2003, Ge et al. 2007) and aquifer compaction (Galloway et al. 1998, Hoffman et al. 2001, Cavalié et al. 2007). Some limits of this technique come from technical sources such as the baseline, the signal-to-noise-ratio, and nonoverlapping Doppler spectral energy. There are also scene-dependent sources of decorrelation mainly related to the atmospheric conditions occurring at the time of radar acquisition and ground surface preservation. The physical changes related to dielectric or geometric variations, more frequent in natural areas, might restrict the interpretation of radar interferometry (Gens and van Genderen 1996). For these reasons, InSAR has been used most successfully in urban areas (Strozzi and Wegmüller 1999; Fruneau and Sarti 2000, Le Mouélic et al. 2005, Chatterjee et al. 2006) though some applications have been found in natural areas (Cavalié et al. 2007, Wdowinski et al. 2008), especially in arid regions (Baer et al. 2002, Closson et al. 2007).

The objective of this article is to examine the performance of conventional InSAR techniques using a series of 29 ERS (European Radar Satellite) images to identify gradual ground deformation associated with sinkhole-prone areas, landslides, and ground deformation in the gypsum outcrops around Zaragoza. We analyse the geological context, coherence in relation to land covers, and the atmospheric conditions at the time of the radar acquisitions. In the absence of a simultaneous, systematic ground survey, the suitability of this technique for detecting slow land subsidence characterized by local morphological expression is of great interest from an applied and scientific point of view. Identifying gradual subsidence can help us to understand the origin of deformation and the mechanism of sinkhole development. Moreover, knowledge about the surface features conditioning InSAR potential in natural areas is of great interest as regards remote sensing of the environment as it pertains to natural risk assessments, and may improve the use of the technique under non ideal conditions.

\section{Study area}

\subsection{Land covers}

Zaragoza is located in the centre of the Ebro Basin, one of the most arid regions of Europe (Herrero and Snyder 1997), with average annual precipitation of $350 \mathrm{~mm}$ and a frequent NW dry wind. Based on the CORINE Land Cover map (IGN 2000), more than 15 different land covers were distinguished in the study area. By grouping them in four general land covers (figure 1) and taking into account their expected contrasting responses in terms of scattering and phase preservation at the C-band wavelength scale, a sufficient surface area is attained. Agricultural areas occupy $60 \%$ of the scene, of 
which $40 \%$ is in dry-farming, mostly winter cereal and fallow land, and $20 \%$ is irrigated farmland, with alfalfa and maize as the dominant crops. Irrigated crops are mainly restricted to the old irrigation systems in the floodplains of the Ebro River and its tributaries. History shows that collapses and karstification hampered the expansion of several irrigation channels in past centuries.

\section{[Figure 1]}

Urban and developed areas occupy less than $2 \%$ of the whole scene. Most natural vegetated areas, $10 \%$ of the scene, were expected to show no change in geometrical surface conditions between the radar acquisitions, due to their low coverage, small size, and slow growth. The scarce green vegetation is composed of Pinus halepensis and other xerophytes, Mediterranean trees and shrubs swayed by the frequent wind. They are isolated and aligned along the borders of the dryfarmed plots, or form small patches at higher altitude, especially in north-facing slopes.

\subsection{Lithology and relief}

The dominant outcropping Miocene Zaragoza Gypsum Formation is only interrupted by the Quaternary alluvial deposits of major river systems (figure 1). The gypsum-rich lithology forms a rounded hilly landscape, with platforms and a network of flat bottom infilled valleys locally named vales. The elevation of the gypseous hills ranges from 300 to $500 \mathrm{~m}$ a.s.1. and clearly differs from that of the alluvial deposits in the Ebro River floodplain, between 160 and $220 \mathrm{~m}$ a.s.l. Some remains of the Tertiary lacustrine limestone cap the gypsum, reaching occasionally 600 and $800 \mathrm{~m}$ in altitude. These are called muelas and planas. This relief, detected by the ERS sensors looking down to the West, is faithfully reproduced by SAR amplitude images.

The landscape morphology, resulting from the interaction of lithology, relief and vegetation, is highlighted by the texture estimated by means of the variation coefficient of the ERS series' mean amplitude on a $5 \times 5$ pixel window basis (figure 2 ). Bright areas extending in a $30-\mathrm{km}$ radius around Zaragoza correspond to scarcely vegetated gypsum and limestone materials. This area represents a relatively unchanging surface in terms of radar signal stability. The urban, developed areas upstream and downstream of Zaragoza and roads are stressed with the maximum brightness, together with the gypsum escarpment, roughly oriented in the direction of satellite illumination. In parallel with the escarpment, the Ebro River and its floodplain area contrast with a uniform darkness resulting from its low backscattering.

Despite the semiarid climate, karstification is caused by dissolution of gypsum and other more soluble salts, such as halite and glauberite. The karstification is intense, especially under the alluvial deposits which usually show abundant ductile and brittle deformation. Karstic subsidence involves different processes such as collapse, suffusion, and sagging (Gutiérrez et al. 2008) and may cause ground subsidence on a regional scale and gravitational morphostructures when operating over long time periods. Moreover, karstic collapses, rotation landslides, piping, diaclases, cracks, and diapiric phenomena distort the gypsum sediments and cause the backward erosion of the escarpment. 
A high density of subsidence structures and sinkholes has been mapped (Soriano and Simón 1995, Gutierrez-Santolalla et al. 2005) in a stretch of the Ebro River valley, about $20 \mathrm{~km}$ upstream and downstream of Zaragoza (figure 2). Evidence of active subsidence and paleosubsidence activation has also been described along the Huerva River valley (Guerrero et al. 2004) and other Ebro River tributaries shown in figure 1. The thickness of alluvium is variable, reaching locally more than $50 \mathrm{~m}$ in depth due to the synsedimentary subsidence. The sinkholes occurrence and their size seem related to the thickness of underlying gypsum and with the anthropogenic concentrations of waters from canals, pipes, and irrigation ditches. Historical and current damages affect the agriculture and infrastructures, including buildings, water-supply systems, railways, motorways, and roads (Gutiérrez et al. 2008). The lack of subsidence features in the Zaragoza metropolitan area seems to be related to the presence of cemented terraces (Gutiérrez, pers. com.). However, the city is currently spreading over the surrounding gypsum outcrops, until now stable under a dry natural regime. In recent decades, subsidence rates estimated in agricultural areas, pavements, and buildings ranged from 1.6 to $11 \mathrm{~cm} /$ year (Simón et al. 2008).

\section{Materials and methods}

\subsection{SAR imagery}

About two hundred ERS-1, ERS-2, and ENVISAT/ASAR images covering the study area were available in the EOLI-SA 3.3 (Earthnet OnLine Interactive) catalogue service. The large archive kept since 1992 was an advantage, together with the 5.33 $\mathrm{GHz}$ frequency band $\left(5.66 \mathrm{~cm}\right.$ wavelength) and 35-day repeat period at a regular $23^{\circ}$ nominal incidence angle. In order to have comparable acquisition geometry, we selected a series of 29 SAR images acquired during the ERS-1 Phase G and ERS-2 Phase A multidisciplinary missions, at 10:25 a.m. in descending mode. The ascending ERS images acquired during the night have the advantage of atmospheric stability, though acquisitions are less frequent.

All the acquired scenes (table 1) belong to track 277 and frame 2766 and were shifted 3 nodes to be centred on the city of Zaragoza. It was not possible to get ERS images belonging to the same season to preserve similar ground surface conditions. They date from 26 April 1995 to 21 December 2000 and belong to all four seasons: 5 from spring, 8 from summer, 7 from autumn, and 9 from winter.

[Table 1]

\subsection{Elevation models}

Two digital elevation models were available to remove the topographic contribution of the interferometric phase: the Spanish photogrammetric elevation model "GIS Oleícola" provided by the Spanish Ministry of Agriculture, Fisheries and Food, produced from a 1997-1998 flight and projected in UTM ED50; and the near global scale 3-arc second 
posting digital elevation model (The Shuttle Radar Topography Mission, SRTM) (Farrr and Kobrick 2000) produced from a flight in February 2000 and edited in WGS84 projection. The former has a 20-m pixel size and absolute vertical accuracy of better than $5 \mathrm{~m}$; the latter, a 90-m pixel size and absolute vertical accuracy of better than $16 \mathrm{~m}$ (Farr et al. 2007). The suitability of both elevation models are discussed in a following section.

\subsection{Differential interferometry}

SAR Interferometry (InSAR) calculates the difference of the phases of two SAR images acquired at different times from the same approximate position in space. Differential interferometry (DInSAR) provides accurate surface deformation by subtracting the topographic phase from SAR interferograms (Massonet and Feigl 1998). By assuming that the scattering characteristics of the ground surface remain undisturbed, this technique enables the mapping of subtle vertical surface movements down to centimetres.

The different factors limiting interferometry applications are basically related to the geometry of radar acquisitions and to ground surface features. The interferogram shows the phase difference $(\Phi)$ which represents the difference in distance measured in the radar line of sight (LOS) and includes mainly topography, orbital shifting, surface deformation, and atmospheric effects:

$$
\phi=\phi_{\text {Topography }}+\phi_{\text {Orbits }}+\phi_{\text {Deformation }}+\phi_{\text {Atmosphere }}
$$

Therefore, three sources of uncertainty arise when calculating the deformation term, $\phi_{\text {Deformation }}$ errors in Digital Elevation Model (DEM) used to correct the topographic phase ( $\left.\phi_{\text {Topography }}\right)$, imprecision in satellite orbits $\left(\phi_{\text {Orbits }}\right)$, and errors produced by atmospheric delay, ( $\phi_{\text {Atmosphere }}$ ) which at low surface elevations are mainly caused by differences in tropospheric water vapour content between scenes (Hanssen 2001).

The first two phase contributions are tackled during the preprocessing step, as explained in the next section. The atmospheric contributions, produced by weather conditions, troposphere heterogeneities, and other atmospheric disturbances, remain almost unpredictable (Hanssen 2001). They can represent about $3 \mathrm{~cm}$ of vertical deformation (Le Mouélic et al. 2005) and the quantification of atmospheric parameters involved in the delay of the radar waves is not usually included in interferometric studies.

3.3.1 Preprocessing. The 29 raw ERS images were focused using an $\omega-\mathrm{K}$ frequency domain algorithm (Cafforio et al. 1991) to guarantee the lowest phase distortion and to preserve the original interferometric coherence. Each image, covering an area of about 
$100 \mathrm{~km} \times 100 \mathrm{~km}$, had a ground resolution of $4-5 \mathrm{~m}$ in azimuth and $20-25 \mathrm{~m}$ in range. The multi-looked images were generated with 5 azimuth looks and one range look resulting in square pixels with a resolution of $20 \mathrm{~m}$ in both directions on the ground. To reduce uncertainty in the satellite positioning in the 29 ERS acquisitions we propagated for our imagery the state vectors (time, velocity and position) from the free and available precise orbits as estimated by Delft University, using gravity models (Scharroo and Visser 1998) with an RMS of 5-7 cm. All the possible master-slave pairs were established from the resulting SAR focused images, with the oldest as the reference or master image. The parameters which conditioned their suitability for producing useful interferograms -i.e. altitude of ambiguity, perpendicular baseline, and difference of Doppler centroids - were analysed. The altitude of ambiguity, $\mathrm{h}_{\mathrm{a}}$, defined by Massonet and Rabaute (1993) as the shift in altitude to produce one topographic fringe, can be considered as the following approximation for ERS satellites:

$$
\mathrm{h}_{\mathrm{a}} \approx \frac{10000 \mathrm{~m}^{2}}{\mathrm{~B}_{\perp}}
$$

where $B_{\perp}$ is the perpendicular baseline between master and slave orbits, or the distance in meters between the satellite antennas in each image pair acquisition. To avoid introducing DEM errors in the topography-removed interferogram we selected only pairs with $\mathrm{h}_{\mathrm{a}}$ larger than $50 \mathrm{~m}$ and $100 \mathrm{~m}$, for the local DEM and the SRTM DEM, respectively.

For conventional SAR interferometry to be successful the critical limit of the baseline in the case of ERS-1 and ERS-2 satellites is about $1100 \mathrm{~m}(\mathrm{Lu}, 2007)$ though the practical limit can be lower. Chang et al. (2007) estimated at $581 \mathrm{~m}$ the maximal effective baseline and noted that the temporal and other decorrelation factors make the practical effective baseline unpredictable. Moreover, for slow land subsidence rates as in the case of this study, a topographic phase can be introduced in the interferograms (Strozzi et al. 2001) even when the baseline is small. To refine the influence that the orbital distance between the two satellite positions has on the interferograms, we analysed the baseline values. We calculated for all pairs the perpendicular baseline using the image-to-image registration offsets and the orbit files.

SAR pairs with a difference between master and slave image Doppler centroids from orbit to orbit higher than the Pulse Repetition Frequency (PRF) are not appropriate for interferometry because they do not overlap their spectrum, causing coherence loss. We considered only the pairs with Doppler differences $<0.10$. A frequency filter was applied in azimuth and range to extract the common spectrum during the interferometric process. Images acquired after 2000 were avoided because of the large and unforeseen Doppler differences due to the significant degradation in attitude and Doppler centroid stability of ERS-2 (Miranda et al. 2005).

3.3.2 Interferogram calculation. We applied the standard two-pass approach described by Massonnet and Feigl (1998) following two different methods implemented 
respectively by SARscape ${ }^{\circledR}$ software, developed by Sarmap, and by the DIAPASON ${ }^{\circledR}$ software (Massonet 1997), developed at the French Space Agency (CNES). The main difference in the application of the two methods was the mode and time of use of the DEM in the interferometric chain. SARscape applied the DEM after calculating the phase difference between master and slave images, while DIAPASON benefited from DEM earlier in the processing, reconstructing the SAR original data over the DEM geometry. In this case, more computation time was necessary. In both cases, whole ERS scenes were processed with the purpose of interpreting the results in a regional geological context.

In a first phase, SARscape was used to co-register the master-slave pairs with a sub-pixel accuracy by means of their shift estimation from the orbits, and subsequent coarse and fine co-registrations. Some parameters such as the correlation window size and number, in azimuth and range, and the signal-to-noise threshold were adapted to avoid the effects of inaccurate orbital parameters or low coherence. In a second phase, SARscape subtracted the topographic phase from the interferogram; for this purpose, the elevation model was converted into radar coordinates and scaled using a backward geocoding approach (Sarmap 2006). Two iterations were required to remove the low frequency phase difference related to the topography. The orbital information was required in the first iteration, and some control points located over the scene in the second iteration.

Afterwards, a spectral shift (Gatelli et al. 1994) and a common Doppler bandwidth filtering were performed (Schwäbisch and Geudtner 1995). The interferometric coherence between the two acquisitions was calculated from the co-registered complex SAR using a 3-pixel sized window following the expression given by Monti Guarnieri et al. (2003). The interferogram was adaptively filtered only where the SNR (Signal Noise Ratio), calculated using a window of fixed 4-pixel size, was greater than 0.25 (Prati et al. 1994).

To verify differences of interferograms generated from the two methods, selected interferograms were generated using DIAPASON software. Master images were lined up with the elevation model by means of a radiometric image simulated from DEM and containing the relief effects. Correlation between master and simulated image was performed using the acquisition start time and the proximal distance of the master image. Following this, a theoretical phase difference, calculated from the orbit data and the elevation model, was applied to correct the raw interferograms, producing a compensated complex interferogram (Massonnet 1997, CNES 1998). The signal-to noise ratio was improved by using a weighted power spectrum filter adapted from that of Goldstein and Werner (1998).

The residual orbital fringes were eliminated using control points in the SARscape processor and an averaged gradient in range and azimuth, calculated from visual computation of orbital fringes, in DIAPASON.

\subsection{Correlation of interferograms}

The variability of the atmospheric conditions between the acquisitions of the images restricts the use of repeat-pass interferometry (Hanssen 2001). From the methods 
applied to detect and eliminate the atmospheric component, the complex correlation of interferograms (Fruneau and Sarti 2000, Chatterjee et al. 2006) has the advantage of simplicity of implementation, requiring only a few interferograms. The method consists of isolating the common deformation between two interferograms. The mean correlation rate of the two interferograms was computed by means of the sum of their phases on a pixel basis and adapting the correlation window size to the spatial scale of the expected displacements. A detailed description of the technique was reported by Fruneau and Sarti (2000).

A sequence of interferograms with no common dates, i.e. no common atmospheric artefacts, was selected. The results were displayed (see section 4.3.2) using an intensityhue-saturation (IHS) transform. We assigned the amplitude of the radar image to the intensity channel, the phase to hue, and the correlation rate to saturation. An inverse IHS transform was performed to reconstruct the red, green, and blue channels.

\section{Results and Discussion}

\subsection{Selection of a digital elevation model}

The local and the SRTM DEMs were applied in some selected interferograms to verify the influence of their difference in vertical precision in the phase difference estimation. No visual differences were observed between results. However, due to the flatness of the sinkhole-prone areas, the accuracy of the local DEM was considered beneficial for ensuring the quality of phase difference estimation. Moreover, since the local DEM flight, 1997, was coincident with many ERS images acquisitions, it should better reproduce the topography of the area. To improve the accuracy of the topographic phase, the geode undulation was estimated via the IBERGEO95 model-based web tool provided by the Spanish Geographic Institute (http://www.cnig.es/) from a representative sample of points of the radar scene. An average value of $15 \mathrm{~m}$ was subtracted from the local DEM.

\subsection{Selection of interferometric pairs}

A total of 406 image pairs were obtained from the combination of the 29 ERS images. Their temporal and spatial baselines and the Doppler centroid difference values were examined in order to judge their usefulness for the interferometric process. As a result, the analysis demonstrated the complexity of obtaining pairs that avoid, as much as possible, the three mentioned decorrelation sources.

As explained in section 3.2.1, to avoid possible errors in the DEM causing a topographic contribution in the phase measurement, only the 103 image pairs with $h_{a}>$ $50 \mathrm{~m}$, were considered. About $30 \%$ of them exhibited a temporal baseline greater than 3 years, and $75 \%$, greater than one year. 
The selected image pairs, with a perpendicular baseline ranging from $4 \mathrm{~m}$ to $385 \mathrm{~m}$, exhibited variable coherence likely related to the time-lag (from 1 to 1610 days) or other acquisition factors. No threshold was imposed regarding the perpendicular baseline values.

Related to the third factor analysed, the Doppler centroid, $65 \%$ of image pairs presented a positive Doppler centroid difference $(D)$ value. The absolute $D$ value varied from 0.4 to $0.4 \times 10^{-3}$, and the highest $D$ corresponds to the pairs with a low temporal baseline. We examined the interferograms with $D>0.10,30 \%$, because a shift in the signal frequency of the radar images can generate a loss of correlation. All of them included an image acquired in 2000 and/or acquired by an ERS-1 sensor. However, given their good coherence and the fact that a spectrum filter is later applied during the interferometric process, we did not discard interferograms with $D>0.10$.

\subsection{Quality of interferograms}

The visual appearance of the fringes and the coherence produced in the interferometric SAR process were used as quality indicators of interferograms. Although the geometrical constraints related to sensor and orbital positioning were addressed, not all image pairs produced good interferograms, due to the presence of noise. Even though precision vectors were used to refine the satellite positions, baseline errors were present in the form of orbital fringes. The residual orbital imprecision was adjusted by applying two different methods, each with its corresponding software. In DIAPASON software, the residual fringes were assimilated by linear adjusting to a regular network modelled and corrected by both gradients, in distance and azimuth. The corners of the DEM and the number of residual fringes in DEM geometry, counted along range and azimuth, gave satisfactory results for small orbital errors. Using SARscape software, several reference points distributed over the scene were needed to calculate the RMSE (Root Mean Squared Error) between orbits and to perform a new interferogram flattening.

The remaining coloured strips and lobes were interpreted as atmospheric artefacts caused by the troposphere or ionosphere delay of the radar signal (Sandwell and Price, 1998; Fruneau and Sarti, 2000). Due to the low surface elevation in the study area, they could be produced mainly by differences in vapour content (Hansen 2001).

One hundred interferograms were evaluated by visual inspection for coherence and atmospheric artefacts.

4.3.1 Interferometric coherence. Temporal decorrelation is very complex and involves the motion of scatterers and changes in soil's dielectric properties due to variations in humidity and temperature (Henderson and Lewis 1998, Chang et al. 2007). This decorrelation can be significant at $\mathrm{C}$-band frequency $(5.5 \mathrm{GHz})$ due to wind, rainfall before or between acquisitions, especially in rough surfaces (Santoro et al. 2007), and the growth of vegetation, especially crops. Occasional rainfall or dew can produce changes in ground dielectric properties even in arid areas (Goldstein 1995; Zebker et al. 1997), limiting the interferometry application. The degree of changes in backscattering characteristics can be quantified by interferometric coherence. 
The interferometric coherence was found to persist over a significant area, in almost half of interferograms, even though $37 \%$ of them were generated from images spanning more than one year, and $10 \%$ from images spanning more than two years. Most of them, about $84 \%$, exhibited a perpendicular baseline $<200 \mathrm{~m}$, and those with a baseline of $>200 \mathrm{~m}$ and very high coherence (with a median of 0.45 ), represented the shortest temporal intervals. All-weather InSAR imaging was a great advantage, although the summer months were supposed to assure chances to produce coherent interferograms. The monthly distribution of our master and slave images proved that only $5 \%$ of interferograms were created from two summer images and $41 \%$ included only one summer image. Nevertheless, due to the slow-growth of the sparse steppe vegetation and the limited extent of tree and shrub areas, the coherence persisted over the natural vegetated areas in spite of the seasonal variation and the time-lag of SAR images (figures 3(a), 3(b)).

To characterize the spatial variation of the main land covers we selected the highest coherence images, and we superimposed the land cover map in a geographic information system. The coherence was estimated by computing the average value in a significant area size for each land cover. The mean coherence varied from 0.50 to 0.19 over the whole scene. Urban and developed areas and natural vegetated areas covered by xerophytes (figure $3(d)$ ) were the most coherent land covers, with a mean coherence of 0.31 and 0.16 , respectively, differing only by $5 \%$. The irrigated areas, with a mean of 0.15 , showed a low coherence, regardless of season and time-lag, except for three pairs spanning 70 days. In the floodplain, the sinkhole-prone areas exhibited low coherence, except for some interferograms with images spanning less than 100 days. However, coherence remained over the roads and urban areas in the floodplain (figure 3(c)), especially upstream of Zaragoza. Dryfarmed areas exhibited an intermediate value, with a mean of 0.17 . The analysis of spatial distribution of the coherent pixels revealed that the maximum coherence persistence occurred in developed areas, gypsum escarpments, and limestone areas covered with sparse xerophytes on shallow soils (figure $3(d)$ ).

\section{[Figure 3]}

The Ebro River floodplain showed low coherence, except for the tandem ERS/1ERS/2 pair and for seven interferograms spanning less than three months. Since this time interval was too short to identify the deformation phenomena under study, only the deformation affecting roads and developed areas in the floodplain was susceptible to detection. Soil surface deformation occurring in irrigated areas was masked by the incoherent pixels in most interferograms. The wide dryfarmed area presented a variable temporal decorrelation due to changes in soil surface roughness related to agricultural practises.

Figure 4 presents the temporal variation of coherence for each land cover as extracted from 4 coherence images corresponding to an increasing time lag, from 105 to 1392 days. The maximum coherence values of each cover had a similar temporal evolution to their mean values, and the land covers were better differentiated by their mean value in the shortest interval and by their maximum value, in the lower coherence interval. This figure reveals that other factors than the time interval influence the decreasing of coherence, though the maximum coherence values corresponded, for all the land covers, to the shortest interval. The coherence decreased from the 125-day 
interval to the 175-day interval, but increased in the following intervals, spanning 245 and 1392 days.

On one hand, the weather conditions, especially rain and wind, produce instability in the scattering elements over a time interval. From the examination of the rains registered in the weather stations of the area, it was observed that only the second pair coincided with rain in four weather stations, with maximum registered rainfall of 20 $\mathrm{mm}$. On the rest of the dates, except for the last, rainfall of $<4 \mathrm{~mm}$ was registered only at one weather station. No rains were registered on the last date. On the other hand, even if the baselines of these image pairs fall under the range of the effective baseline, the second pair exhibited a value of $282 \mathrm{~m}$, much higher than the baseline value of the other three pairs, $78 \mathrm{~m}, 27 \mathrm{~m}$, and $44 \mathrm{~m}$, respectively. Therefore, a combined effect of wet soil surface conditions and a high baseline could have a much greater effect than time-lag on the variability of coherence.

\section{[Figure 4]}

4.3.2 Atmospheric artefacts. The interferograms exhibited significant phase variations which changed location on different dates. Broken parallel fringes, bubbles, and lobed fringes of different sizes appeared in the areas of high coherence. Almost $29 \%$ of interferograms were affected by those artefacts, $72 \%$ of them to a high or very high degree (figure 5). Regarding the topography of the area, with $500 \mathrm{~m}$ of height difference, no systematic fringe pattern related to the rounded gypsum hills was observed. Therefore, these artefacts were related to the atmosphere conditions at the time of radar acquisitions, especially to variations in water vapour, temperature, or pressure. These variations contrast with the fact that the area is located in one of the most arid regions in Europe. In winter, fog is frequent in the floodplains early in the morning, but a dry NW wind is much more common, blowing with a frequency of $40 \%$ and a mean velocity of $30 \mathrm{~km} / \mathrm{h}$. Atmospheric noise was checked for by: (1) verifying the spatial variability of the fringes in independent interferometric pairs, (2) recognizing the atmospheric effects in pairs sharing a common date, and (3) verifying that all these artefacts were not related to the topography.

\section{[Figure 5]}

Rain occurring at the time of data acquisition entails changes in the dielectric constant of the surface material causing decorrelation. Rain is not an atmospheric artefact per se, though its occurrence at the time of data acquisition involves cloudy conditions and temporary disturbances in the atmosphere. To justify the high occurrence of atmospheric perturbations in the interferograms we examined the rains recorded at the radar acquisition dates, and the free and available Landsat quicklooks and METEOSAT images from their web catalogues. The Zaragoza WMO and 15 weather stations belonging to the National Weather Institute (I.N.M) network (figure 6) were considered for this analysis. As a result, a high occurrence of rains of variable magnitude was observed at the radar acquisition dates as 21 of the 29 ERS dates were rainy at at least one weather station. On seven dates, no rains were recorded in the area, including three dates in 1995, the driest year from the period studied. As an exception, 10 August 1995 (1594 orbit) was assumed to be very cloudy because 12 weather stations, the maximum in the period studied, registered simultaneous rains. In December 1996 (8608 orbit), 8 weather stations registered rains, with a mean of $0.9 \mathrm{~mm}$; in 
January 1997 (9109 orbit) and October 2000 (28648 orbit), 7 weather stations registered rains with a mean of $2.9 \mathrm{~mm}$ and $11 \mathrm{~mm}$, respectively. The daily local precipitation in the 21 rainy dates studied ranged from $1 \mathrm{~mm}$ to $40 \mathrm{~mm}$, and the mean precipitation on each date, computed for the whole scene from the 16 weather stations, was $<11 \mathrm{~mm}$. Rainfall exceeded $2 \mathrm{~mm}$ on only 14 of the 29 ERS SAR dates.

This analysis illustrates the scarcity and the irregular spatial distribution of the rains on the radar acquisition dates. Some bias could occur due to the lack of coincidence between the manual raingauge reading time and that of the satellite pass. Moreover, the morning raingauge reading included the rains occurred 24-h previous to each radar observation instance. This is exemplified with the free-cloud Landsat TM image from 3 October 1996, acquired at 10:25, while one weather station registered 2 $\mathrm{mm}$ (in the $24 \mathrm{~h}$ previous). Consequently, $77 \%$ of the image pairs contained a rainy date at at least one weather station. Taking into account only rain over $2 \mathrm{~mm}$, on 7 dates between 3 and 7 weather stations registered rain; on 8 dates, only one weather station registered rain.

\section{[Figure 6]}

To be able to infer cloudy conditions in the whole scene we examined the concurrent Landsat images belonging to the 199/31 track/frame from the available Eurimage EiNet (http://www.eurimage.com/q1/), and the METEOSAT first generation (http://badc.nerc.ac.uk/browse/badc/meteosat) catalogues. These images roughly matched the time of the ERS passes, 10:25 a.m., although the number of days between the dates of ERS and the nearest Landsat images varied from 1 to 11 . From the two concurrent Landsat dates we verified the only cloudless date of our set, on 3 October 1996. The rest of the Landsat images were very cloudy, some of them with a parallel (strip) pattern recognized in some interferograms (figure 7). All the available METEOSAT images simultaneous to ERS images in 2000 clearly showed cloudy cover and high vapour content over the whole imaged ERS scene. Due to the different spatial resolution of ERS and METEOSAT scenes, we did not look for a detailed verification of atmospheric noise in each interferogram. However, the ubiquitous cloudy conditions at the time of the ERS acquisitions confirmed the atmospheric origin of the frequent artefacts and fringes observed in many of the highly coherent interferograms.

\section{[Figure 7]}

The correlation of interferograms was used to dilute atmospheric noise. We correlated two independent interferograms, i.e. created with four images from different dates, representing a time interval of 5 and 6 months, respectively. We correlated this result with a new interferogram spanning 10 months. All the correlated interferograms shared a common time interval. Therefore, a potential common ground deformation was preserved along the correlation steps. The IHS transform was applied to represent the resulting deformation fringes on the outskirts of Zaragoza city (figure 8). The noise was highly reduced whereas the phase information remained only in a few urban and developed areas, and the detection of a fringe pattern related to ground motion was not possible. Unfortunately, a new correlation did not improve this result because the number of pixels with phase information decreased.

\section{[Figure 8]}




\subsection{Detailed analysis of deformation areas}

The two methods used for calculating the interferograms, implemented in DIAPASON and SARscape, respectively, provided similar results in terms of fringe patterns on the whole scene. However, local differences were noticed due to the different techniques used for the final visualized product, related mainly to the different pixel size and filtering technique. Taking into account the small size of the deformation features studied in this work, the resolution of the final product highly conditioned the interpretation of the interferograms. In general, the interferograms filtered with the weighted power spectrum filter implemented in DIAPASON performed a helpful smoothing to preserve the continuity of the fringes, but resulted in a loss of phase information in small and isolated areas. For comparison purposes, the phase coding and data type resulting from both methods were customized. The analysis was best compensated for by comparing the unfiltered interferograms calculated with DIAPASON with those filtered from SARscape (figure 9).

[Figure 9]

The best interferograms, i.e. those with highest coherence and without perceptible atmospheric artefacts, were selected to analyse the fringes related to ground deformation phenomena. Unlike the fringes produced by atmospheric effects, those related to slow deformation are supposed to occur at the same location in independent interferometric pairs. At a detailed scale, a certain spatial variation of the deformation is assumed because evaporite dissolution and deformation development can vary according to active processes (dissolution, compaction and consolidation of sediments, water level changes, landslides, etc.) and anthropogenic activity.

In general, clear fringes were lacking or poorly defined even after the filtering of the interferograms. Interpreting and comparing the fringe colour variation and distribution from individual interferograms was cumbersome, as the fringes were not understandable in terms of continuity and extent. The application of advanced DInSAR techniques, which will be the subject of a forthcoming article (Castañeda et al. 2009) allowed the identification of local deformation areas in (1) a salt mine over the hilly gypsum outcrops, (2) the gypsum escarpment, and (3) the sinkhole-prone area at the bottom of the valley. These three sites were therefore examined in our interferograms (figure 10(a)).

A deformation fringe pattern identified in the gypsum outcrops corresponds to a slow deformation produced by mining subsidence in the Remolinos area (figure 10(b)), where an interstratified halite unit is being extracted from Roman times. The three interferograms analysed correspond to three independent image pairs 2095-7105, 17626-24640, and 7606-20632, and represent an increasing time interval of 350 days, 490 days, and 910 days, respectively. In this area covered with xerophytes, coherence was high enough to allow for well-developed fringes. The number of fringes increases with the time interval (figure 10(b)), each fringe cycle corresponding to a ground displacement of half the radar wavelength, $28 \mathrm{~mm}$, in the satellite-ground line of sight. Up to now mining subsidence was not known in the Remolinos mine. The swelling of the soil due to the presence of esmectites in the clay fraction or to the different penetration of electromagnetic radiation (Gens and van Genderen 1996) was discarded because there are no significant lithological differences. Field surveys together with 
sustained interferometric monitoring will make possible corroboration of the mining deformation and inference of the ground motion on the dates of this study, from 1995 to 2000 .

A second pattern of poorly to moderately-developed fringes was observed over the gypsum escarpment in three independent interferograms constructed from 7606-10612, 6103-9606, and 2095-7105 image pairs, which represented an increasing time interval of 70, 245, and 350 days, respectively (figure 10(c)). This deformation corresponds to active slope movements occurring in a small segment along the linear escarpment upstream of Zaragoza city, the most active area. We discard the topographic origin of these fringes because the gypsum escarpment extends for more than $70 \mathrm{~km}$ with a linear trace, and no systematically associated topographic fringes are observed alongside. Unlike the ground deformation identified in the salt mine, these elongated fringes do not increase in number as the time interval increases. It is probably due to the different mass movement types in the scarp which limit InSAR phase preservation. Moreover, two other factors can be taken into account: (1) the parallelism between the NW-SE-trending escarpment and the ERS satellite line of sight which limits the capability to detect the deformation; and (ii) the upward and horizontal displacements involved in the rotational landslides that might hamper the preservation of well-developed fringes over time.

Figure 10(d) displays a third fringe pattern occurring in the floodplain and lower terraces upstream of Zaragoza. In this area, active subsidence associated to sinkholes has been revealed by geomorphological investigations (Soriano and Simón 1995, Gutiérrez et al. 2007, Galve et al. 2009). The progressive subsidence and deformation affects buildings and roads; some factories have been demolished and the N-232 highway is re-asphalted every year. Three independent interferograms constructed with the image pairs 1594-6103, 2095-8608, and 7606-20632 were analysed, representing a time interval varying from 315 days to 910 days. Well-developed fringes are not visible although repetitive patterns appear in the same location, an industrial state where Simón et al. (2008) measured subsidence rates of 3.2-4 cm/year by leveling. Buildings are constructed in a large active sinkhole artificially filled but clearly identifiable in old aerial photographs and topographic maps (Galve et al. 2009).

[Figure 10]

These examples illustrate two main advantages of the DInSAR technique: the potential to detect slight ground deformation and its application over large areas. Field knowledge was crucial to obtain information from the interferograms, and their filtering improved visual interpretation since the signal was frequently blurred by noise. The main disadvantages include (1) the small size of the surface deformation features, specially the limited extent of the subsidence areas related to sinkhole development, (2) the loss of coherence due to agricultural practises, and (3) the shortness of the five-year temporal interval for these slow phenomena. The technique, sensitive to the resolution of the topographic elevation model, gives similar results with the two different methods used for calculating the interferograms.

This study shows the potential of conventional radar interferometry to study different deformation phenomena in evaporite areas, including mining subsidence, landslides, and subsidence related to sinkhole development. Interferometry and especially coherence provided characteristics of the Zaragoza surroundings related to 
lithology and land covers which should prove to be of interest for future thematic studies.

The availability of favourable parameters dictates the success of conventional interferometry and advanced DInSAR techniques allow for the refining of these results by avoiding the influence of atmospheric artefacts and decorrelation. In a forthcoming article we shall provide quantified ground motion information for the area around Zaragoza city during identical time interval (Castañeda et al. 2009).

\section{Conclusions}

Conventional SAR interferometry has been applied for the first time to the study of deformation areas in evaporites around Zaragoza. The technique proved to be of interest to study a wide region, although the local nature of the deformation phenomena was an important constraint. A dedicated and applied analysis allowed us to determine the limiting factors of our interferograms. Coherence was not a limiting factor for interferogram calculation, though the higher sinkhole density area was decorrelated due to agricultural practises. Atmospheric noise was much more frequent than expected for such an arid area, hampering the analysis of many interferograms.

We detected widespread fringe patterns related to the slow deformation of evaporites with a time lag of five years. The deformation is produced by different natural and human-induced processes, mainly subsidence by evaporite bedrock dissolution, scarp motion and landslides, and mining subsidence. The two interferometric methods employed provided similar results with small differences. The deformation fringes are to be verified in a forthcoming article by advanced multitemporal DInSAR, and future studies must be accompanied by precise groundbased levelling measurements. From an applied point of view, the products of interferometry have great potential, whether alone or combined with other thematic information.

\section{Acknowledgments}

C. Castañeda received a grant from the Spanish Ministry of Education and Scientific Research under the responsibility of Dr. A. Rigo, at the Laboratoire de Dynamique Terrestre et Planétaire (Observatoire Midi-Pyrénées). The work was funded by Spanish projects AGL2006-01283/AGR and PM008/2007. The European Space Agency provided the ERS images under the Cat-1P-3462 project. We acknowledge the comments of the two anonymous reviewers that helped to improve the manuscript. We also acknowledge the kind collaboration of Sarmap, Altamira Information, and F.J. González-Matesan (Spanish Geographical Institute), and the support of Dr. J. Herrero. 


\section{References}

BAER, G., SCHATTNER, U., WACHS, D., SANDWELL, D., WDOWINSKI, S. and FRYDMAN, S., 2002, The lowest place on Earth is subsiding - An InSAR (interferometric synthetic aperture radar) perspective. Geological Society of America Bulletin, 114, pp.12-23.

BENITO, G., GUTIÉRREZ, F., PÉREZ-GONZÁLEZ, A. and MACHADO, M.J., 2000, Geomorphological and sedimentological features in Quaternary fluvial systems affected by solution-induced subsidence (Ebro Basin, NE-Spain). Geomorphology, 33, pp. 209-224.

CAFFORIO, C., PRATI, C. and ROCCA, F., 1991, SAR data focusing using seismic migration techniques. IEEE Transactions Aerospace and Electronics Systems, 27(2), pp.194-207.

CASTAÑEDA, C., GUTIÉRREZ, F., MANUNTA, M. and GALVE, J.P., 2009, Detecting and measuring ground deformation caused by sinkholes, mining subsidence and landslides in the Ebro River valley (NE Spain) by means of the SBAS DInSAR technique. Earth Surface Processes and Landforms, 34, pp.15621574.

CAVALIÉ, O., DOIN, M.P., LASSERRE, C. and BRIOLE, P., 2007, Ground motion measurement in the Lake Mead area, Nevada, by differential synthetic aperture radar interferometry time series analysis: Probing the lithosphere rheological structure. Journal of Geophysical Research-Solid Earth, 112, B03403.

CHANG, Z., ZHANG, J., GONG, H., ZHANG, J. and ZHAO, W., 2007, 'Maximal effective baseline' for conventional SAR interferometry. International Journal of Remote Sensing, 28, pp. 5603-5615.

CHATTERJEE, R.S., FRUNEAU, B., RUDANT, J.P., ROY, P.S., FRISON, P.L., LAKHERA, R.C., DADHWAL, V.K. and SAHA, R., 2006, Subsidence of Kolkata (Calcutta) City, India during the 1990s as observed from space by differential synthetic aperture radar interferometry (D-InSAR) technique. Remote Sensing of Environment, 102, pp. 176-185.

CLOSSON, D., LAMOREAUX, P.E., ABOU KARAKI, N. and AL-FUGHA, H., 2007, Karst system developed in salt layers of the Lisan Peninsula, Dead Sea, Jordan. Environmental Geology, 52, pp. 155-172.

C.N.E.S. (Centre National d'Etudes Spatiales), 1998, Philosophy and Instructions for the use of DIAPASON interferometry software system developed at CNES, Toulouse. Technical document.

FARR, T. and KOBRICH, M., 2000, Shuttle radar topographic mission produces a wealth of data, Eos, Transactions, American Geophysical Union, 81, pp. 583-585.

FARR, T.G., ROSEN, P.A., CARO, E., CRIPPEN, R., DUREN, R., HENSLEY, S., KOBRICK, M., PALLER, M., RODRIGUEZ, E., ROTH, L., SEAL, D., SHAFFER, S., SHIMADA, J., UMLAND, J., WERNER, M., OSKIN, M., BURBANK, D. and ALSDORF, D., 2007, The shuttle radar topography mission. Reviews of Geophysics, 45. 
FRUNEAU, B. and SARTI, F., 2000, Detection of ground subsidence in the city of Paris using radar interferometry: isolation of deformation from atmospheric artifacts using correlation. Geophysical Research Letters, 27, pp. 3981-3984.

GALlOWAY, D.L., HUDNUT, K.W., INGEBRITSEN, S.E., PHILLIPS, S.P., PELTZER, G., ROGEZ, F. and ROSEN, P.A., 1998, Detection of aquifer system compaction and land subsidence using interferometric synthetic aperture radar, Antelope Valley, Mojave Desert, California. Water Resources Research, 34, pp. 2573-2585.

GALVE, J.P., GUTIÉRREZ, F., LUCHA, P., BONACHEA, J., CENDRERO, A., GIMENO, M.J., GUTIÉRREZ, M., PARDO, G., REMONDO, J. and SÁNCHEZ, J.A., 2009, Sinkholes in the salt-bearing evaporite karst of the Ebro River valley upstream of Zaragoza city (NE Spain). Geomorphological mapping and analysis as a basis for risk management. Geomorphology, 108, pp. 145-158.

GATELli, F. GUAMIERI, A.M., PARIZZI, F., PASQUALI, P., PRATI, C. and ROCCA, F., 1994, The wavenumber shift in SAR interferometry. IEEE Transactions on Geoscience and Remote Sensing, 32, pp. 855-865.

GE, L.L., CHANG, H.C. and RIZOS, C., 2007, Mine subsidence monitoring using multi-source satellite SAR images. Photogrammetric Engineering and Remote Sensing, 73, pp. 259-266.

GENS, R. and VAN GENDEREN, J.L., 1996, Review article: SAR interferometry-issues, techniques, applications. International Journal of Remote Sensing, 17, pp. 1803-1835.

GOLDSTEIN, R., 1995, Atmospheric limitations to repeat-track radar interferometry. Geophysical Research Letters, 22, pp. 2517-2520.

GOLDSTEIN, R. and WERNER, C.L., 1998, Radar interferogram filtering for geophysical applications. Geophysical Research letters, 25, pp. 4035-4038.

GUERRERO, J., GUTIERREZ, F. and LUCHA, P., 2004, Paleosubsidence and active subsidence due to evaporite dissolution in the Zaragoza area (Huerva River valley, NE Spain): processes, spatial distribution and protection measures for transport routes. Engineering Geology, 72, pp. 309-329.

GUTIÉRREZ, F., ARAUZO, T., and DESIR G., 1994, Deslizamientos en el escarpe de Alfajarín (Zaragoza). Cuaternario y Geomorfología, 8, pp. 57-68.

GUTIERREZ-SANTOLALLA， F., GUTIERREZ-ELORZA， M., MARIN， C., MALDONADO, C. and YOUNGER, P.L., 2005, Subsidence hazard avoidance based on geomorphological mapping in the Ebro River valley mantled evaporite karst terrain (NE Spain). Environmental Geology, 48, pp. 370-383.

GUTIÉRREZ, F., GALVE, J.P., GUERRERO, J., LUCHA, P., CENDRERO, A., REMONDO, J., BONACHEA, J., GUTIÉRREZ, M. and SÁNCHEZ, J.A., 2007, The origin, typology, spatial distribution and detrimental effects of the sinkholes developed in the alluvial evaporate karst of the Ebro River valley downstream of Zaragoza city (NE Spain). Earth Surface Processes and Landforms, 32, pp. 912928. 
GUTIÉRREZ, F., CALAFORRA, J.M., CARDONA, F., ORTÍ, F., DURÁN, J.J. and GARAY, P., 2008, Geological and environmental implications of the evaporite karst in Spain. Environmental Geology, 53, pp. 951-965.

HANSSEN, R.F., 2001, Radar Interferometry: data interpretation and error analysis. Kluwer Academic Publishers (Ed.) (Dordrecht), pp.308.

HENDERSON, F. and LEWIS, A.J., 1998, Principles and applications of imaging radar: manual of remote sensing, 3th ed., vol 2, John Wiley and Sons, Inc., New York, USA, pp.750.

HERRERO, J. and SNYDER, R.L., 1997, Aridity and irrigation in Aragón, Spain. Journal of Arid Environments, 35, pp. 535-547.

HOFFMANN, J., ZEBKER, H.A., GALLOWAY, D.L. and AMELUNG, F., 2001, Seasonal subsidence and rebound in Las Vegas Valley, Nevada, observed by synthetic aperture radar interferometry. Water Resources Research, 37, pp. 15511566.

I.G.N. (Instituto Geográfico Nacional), 2000, Corine Land Cover (España), Instituto Geográfico Nacional (Ed.) (Madrid, Spain), CDRom.

LE MOUÉliC, S., RAUCOUlES, D., CARNEC, C. and KING, C., 2005, A least squares adjustment of multi-temporal InSAR data : Application to the ground deformation of Paris. Photogrammetric Engineering and Remote Sensing, 71, pp. 197-204.

LU, Z., 2007, InSAR imaging of volcanic deformation over cloud-prone areas Aleutian Islands. Photogrammetric Engineering and Remote Sensing, 73, pp. 245257.

MIRANDA, N., ROSICH, B., SANTELLA, C. and GRION, M., 2005, Review of the impact of ERS-2 piloting modes on the SAR Doppler stability. ESA SP-572. In Proceedings of the 2004 ENVISATand ERS Symposium, Salzburg, Austria.

MASSONNET, D., 1997, Producing ground deformation maps automatically: the DIAPASON concept. IGARSS'97 Proceedings, IEEE International, 3, pp. 13381340.

MASSONNET, D. and FEIGL, K.L., 1998, Radar interferometry and its application to changes in the earth's surface. Reviews of Geophysics, 36, pp. 441-500.

MASSONNET, D. and RABAUTE, T., 1993, Radar interferometry: limits and potencial. IEEE Transactions on Geoscience and Remote Sensing, 31, pp. 455464.

MASSONNET, D., ROSSI, M., CARMONA, C., ADRAGNA, F., PELTZER, G., FEIGL, K. and RABAUTE, T., 1993, The displacement field of the Landers earthquake mapped by radar interferometry. Nature, 364, pp. 138-142.

MONTI GUARNIERI, A., GUCCIONE, P., PASQUALI, P. and DESNOS, Y.L., 2003, Multi-mode ENVISAT ASAR interferometry: Techniques and preliminary results. IEEE Proceedings Radar Sonar and Navigation, 150, pp. 193-200. 
PRATI C., ROCCA F., MONTI GUARNIERI A. and PASQUALI P., 1994, Interferometric Techniques and Applications - ESA Study Contract Report. Contract N.3-7439/92/HGE-I.C.

RAUCOUlES, D., LE MOUELIC, S., CARNEC, C., MAISONS, C. and KING, C., 2003, Urban subsidence in the city of Prato (Italy) monitored by satellite radar interferometry. International Journal of Remote Sensing, 24, pp. 891-897.

SANDWELL, D.T. and PRICE, E.J., 1998, Phase gradient approach to stacking interferograms. Journal of Geophysical Research-Solid Earth, 103, pp. 3018330204.

SANTORO, M., ASKNE, J.I.H., WEGMULLER, U. and WERNER, C.L., 2007, Observations, modeling, and applications of ERS-ENVISAT coherence over land surfaces. IEEE Transactions on Geoscience and Remote Sensing, 45, pp. 26002611.

SARMAP, 2006, SARscape ${ }^{\circledR}$ Interferometry Module. User Guide. Sarmap S.A., (Switzerland).

SCHARROO, R. and VISSER, P., 1998, Precise orbit determination and gravity field improvement for the ERS satellites. Journal of Geophysical Research-Oceans, 103, pp. 8113-8127.

SCHWABISCH, M. and GEUDTNER, D., 1995, Improvement of Phase and Coherence Map Quality Using Azimuth Prefiltering: Examples from ERS-1 and X-SAR. IGARSS'95 Proceedings, IEEE International, 1, pp. 205-207.

SIMÓN, J.L., SORIANO, M.A., ARLEGUI, L.E., GRACIA, J., LIESA, C.L. and POCOVI, A., 2008, Space-time distribution of ancient and active alluvial karst subsidence: examples from the central Ebro Basin, Spain. Environmental Geology, 53, pp. 1057-1065.

SORIANO M.A. and SIMÓN J.L., 1995, Alluvial dolines in the central Ebro Basin, Spain: a spatial and developmental hazard analysis. Geomorphology, 11, pp. 295309.

STROZZI, T. and WEGMULLER, U., 1999, Land subsidence in Mexico City mapped by ERS differential SAR interferometry. IGARSS '99 Proceedings, IEEE International, 4, pp. 1940-1942.

STROZZI, T., WEGMÜLLER, U., TOSI, L., BITELLI, G. and SPRECKELS, V., 2001, Land subsidence monitoring with differential SAR interferometry. Photogrammetric Engineering and Remote Sensing, 67, pp. 1261-1270.

WDOWINSKI, S., KIM, S.W., AMELUNG, F., DIXON, T., MIRALLES-WILHELM, F. and SONENSHEIN, R., 2008, Space-based detection of wetlands' surface water level changes from L-band SAR interferometry. Remote Sensing of Environment, 112, pp. 681-696.

ZEBKER, H.A., ROSEN, P.A. and HENSLEY, S., 1997, Atmospheric effects in interferometric synthetic aperture radar surface deformation and topographic maps. Journal of Geophysical Research-Solid Earth, 102, pp. 7547-7563. 


\section{Table and Figure captions}

Table 1. Sensor, date, and orbit number of the SAR images selected for this study. Their temporal interval, referred to the date of the first image, is also noted.

Figure 1. Location of the study area and the main land covers of the imaged scene, simplified from Corine LC 2000. The major rivers are named.

Figure 2. The texture obtained by means of the coefficient of variation of the ERS SAR image series' mean amplitude shows a bright, nearly circular area around Zaragoza representing the scarcely vegetated gypsum and limestone outcrops; roads are also clearly visible.

Figure 3. The coherence of the study area for a 71 day time-lag (a) and a 700 dayinterval (b). The urban areas (in white) and the areas with geomorphological evidence of subsidence and deformation (white polygons) are superimposed on the mean coherence image (c). The coherent outcrops around Zaragoza are dominated by rounded gypsum hills with scarce xerophytic vegetation and infilled valleys (d).

Figure 4. Mean (a) and maximum (b) coherence values of the main land covers in the area, for four coherence images with an increasing time interval. Natural vegetation has been divided into two classes: green vegetation and xerophytes.

Figure 5. Examples of atmospheric artefacts resulting from independent interferograms constructed from image pairs 20766-7105 (a), 9610-10612 (b), and 11614-14620 (c). All interferograms show a large coherent area with visible phase noise (i.e. coloured stripes and lobes) produced by troposphere heterogeneities.

Figure 6. Maximum precipitation (right column) registered in the study area on each ERS SAR image date, and the number of simultaneous weather stations registering the rain (top). The length of the bars illustrates the amount of rain.

Figure 7. a: Multiple atmospheric artefacts appear in the interferogram obtained from the image pairs 8608-9610, with the weather stations superimposed; b: METEOSAT image coincident with the 8608 image acquisition, with the study area showed; c: Landsat TM image of the same area acquired on 11 December 1996, a day before the 8608 image acquisition in $b$.

Figure 8. Atmospheric noise was removed by applying the correlation of three interferograms (obtained from 7696-9610, 8608-10612, and 8608-12616 image pairs). The phase information remained in urban areas upstream of Zaragoza. The amplitude image was used as background.

Figure 9. Detail of the interferogram obtained from the pair 17626-24640 showing comparable results from DIAPASON (a) and SARscape (b) methods. Only the second is filtered.

Figure 10. (a): Location of the three areas (numbered) analysed in a sequence of filtered and independent interferograms that represent increasing time intervals; (b): In area 1, the number of deformation fringes increases with the time interval in the Remolinos salt mine; (c): In area 2, a variable fringe pattern is detected along the gypsum escarpment extending NW-SE parallel to the river, in blue; (d): In area 3, 
a small, persistent fringe pattern is detected in a well known subsidence area related to sinkhole development that affects buildings and roads. All the interferograms are superimposed to ortophotographs using a slight transparency. 
865 Table 1. Sensor, date, and orbit number of the SAR images selected for this study. Their 866 temporal interval, referred to the date of the first image, is also noted.

\begin{tabular}{cccccc}
\hline Sensor & Year & Month & Day & $\begin{array}{c}\text { Orbit } \\
\text { number }\end{array}$ & $\begin{array}{c}\text { Days' interval } \\
\text { from the date of } \\
\text { the first image }\end{array}$ \\
\hline ERS-1 & 1995 & 4 & 26 & 19764 & 0 \\
ERS-1 & 1995 & 7 & 5 & 20766 & 70 \\
ERS-2 & 1995 & 8 & 10 & 1594 & 106 \\
ERS-2 & 1995 & 9 & 14 & 2095 & 141 \\
ERS-1 & 1996 & 4 & 10 & 24774 & 350 \\
ERS-2 & 1996 & 6 & 20 & 6103 & 421 \\
ERS-2 & 1996 & 8 & 29 & 7105 & 491 \\
ERS-2 & 1996 & 10 & 3 & 7606 & 526 \\
ERS-2 & 1996 & 12 & 12 & 8608 & 596 \\
ERS-2 & 1997 & 1 & 16 & 9109 & 631 \\
ERS-2 & 1997 & 2 & 20 & 9610 & 666 \\
ERS-2 & 1997 & 3 & 27 & 10111 & 701 \\
ERS-2 & 1997 & 5 & 1 & 10612 & 736 \\
ERS-2 & 1997 & 7 & 10 & 11614 & 806 \\
ERS-2 & 1997 & 9 & 18 & 12616 & 876 \\
ERS-2 & 1997 & 11 & 27 & 13618 & 946 \\
ERS-2 & 1998 & 2 & 5 & 14620 & 1016 \\
ERS-2 & 1998 & 9 & 3 & 17626 & 1226 \\
ERS-2 & 1999 & 4 & 1 & 20632 & 1436 \\
ERS-2 & 1999 & 6 & 10 & 21634 & 1506 \\
ERS-1 & 1999 & 7 & 14 & 41808 & 1540 \\
ERS-1 & 1999 & 10 & 27 & 43311 & 1645 \\
ERS-2 & 1999 & 10 & 28 & 23638 & 1646 \\
ERS-2 & 2000 & 1 & 6 & 24640 & 1716 \\
ERS-1 & 2000 & 2 & 9 & 44814 & 1750 \\
ERS-2 & 2000 & 3 & 16 & 25642 & 1786 \\
ERS-2 & 2000 & 8 & 3 & 27646 & 1926 \\
ERS-2 & 2000 & 10 & 12 & 28648 & 1996 \\
ERS-2 & 2000 & 12 & 21 & 29650 & 2066 \\
\hline & & & & &
\end{tabular}


$869 \quad$ Figures

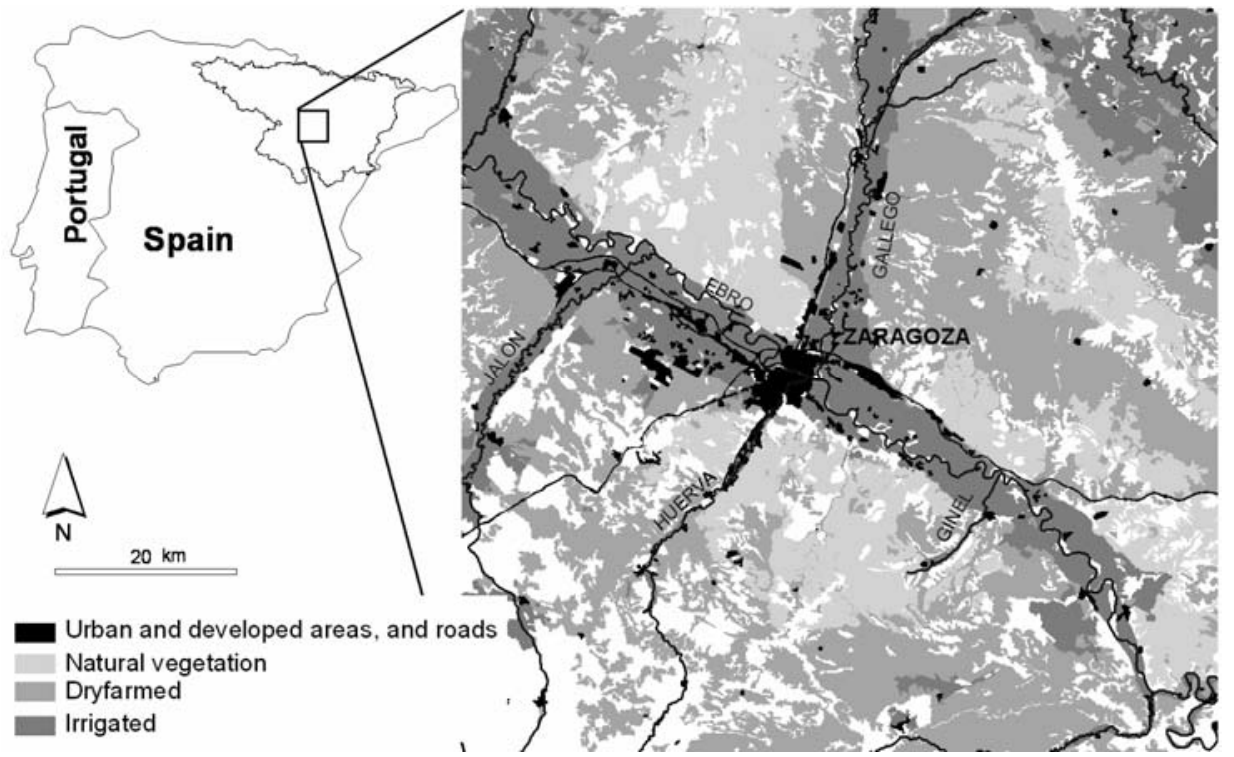

$871 \quad$ Figure1

872

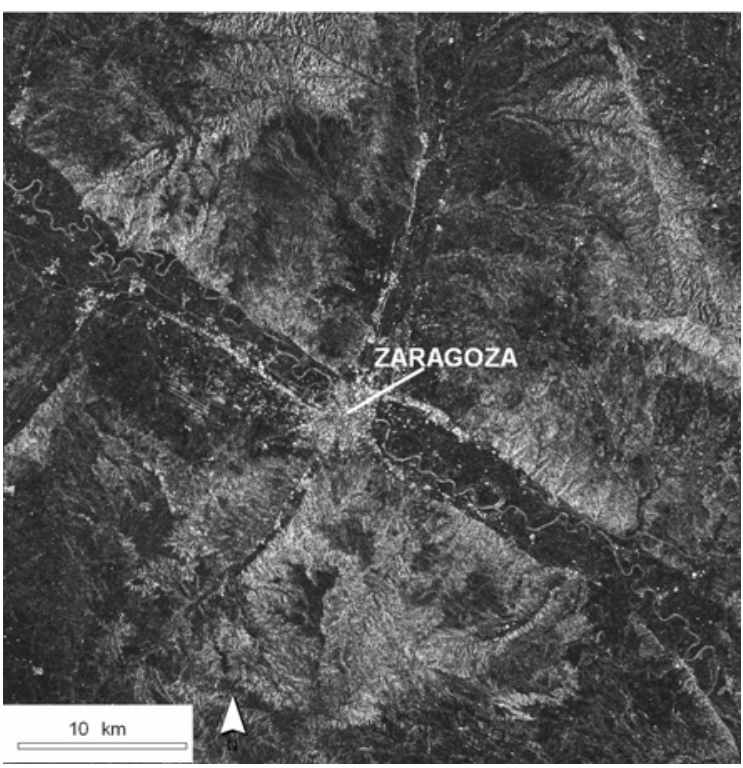

$875 \quad$ Figure 2 

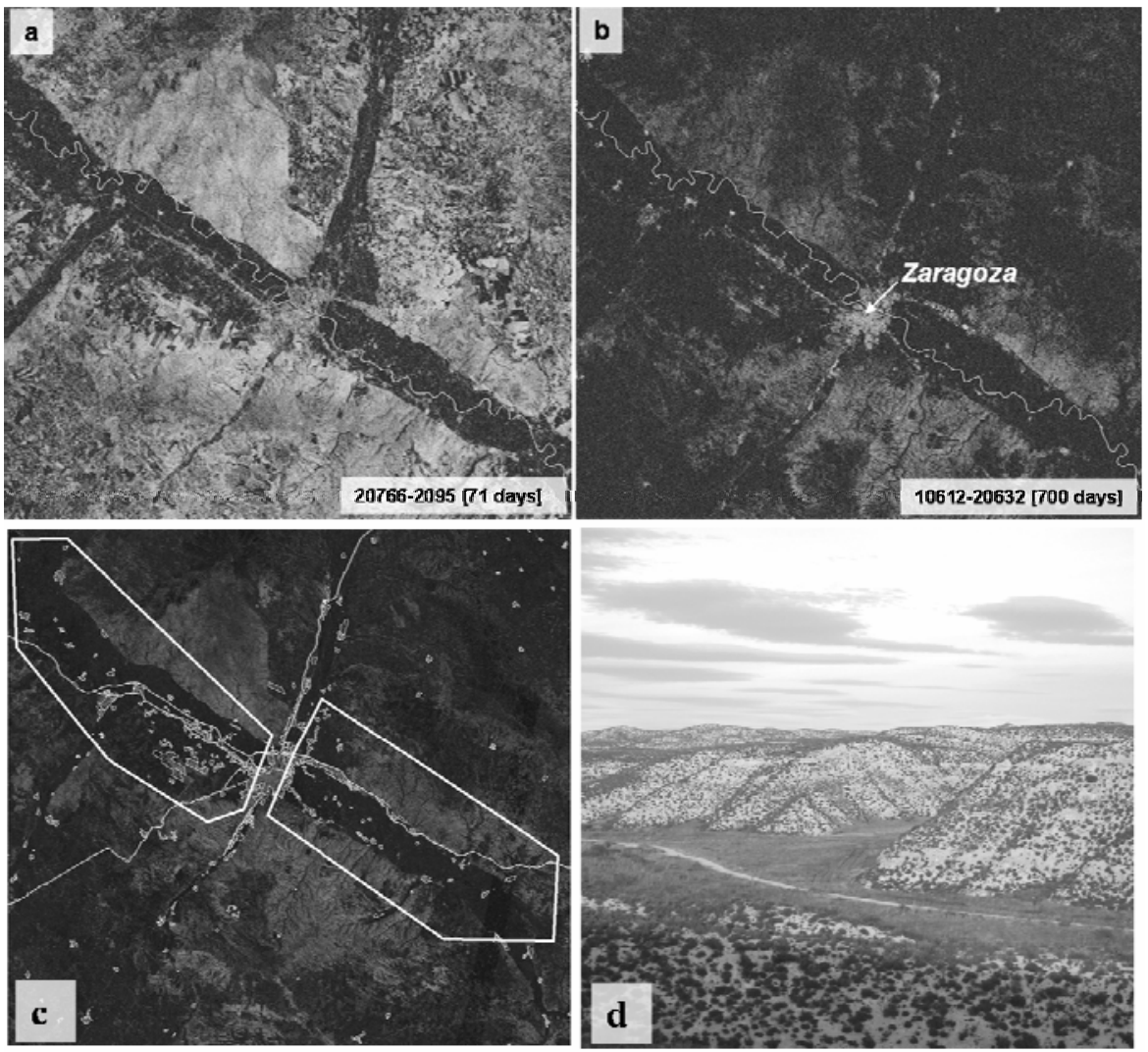

$877 \quad$ Figure 3

878
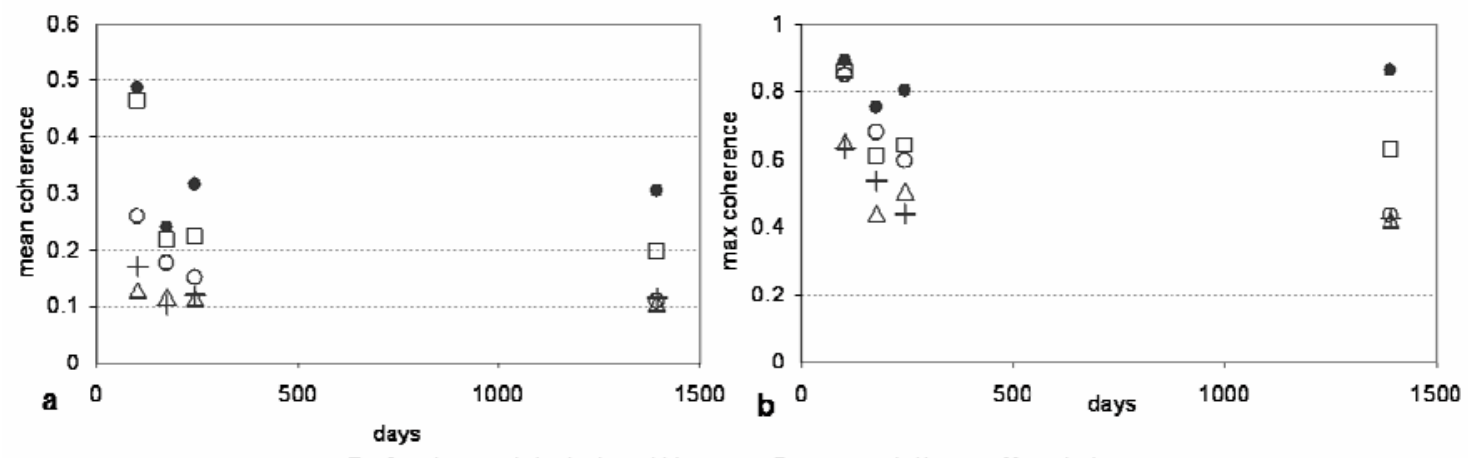

879

oDryfarming $\Delta$ Irrigated Urban +Green vegetation $\square$ Xerophytes

$880 \quad$ Figure 4

881 

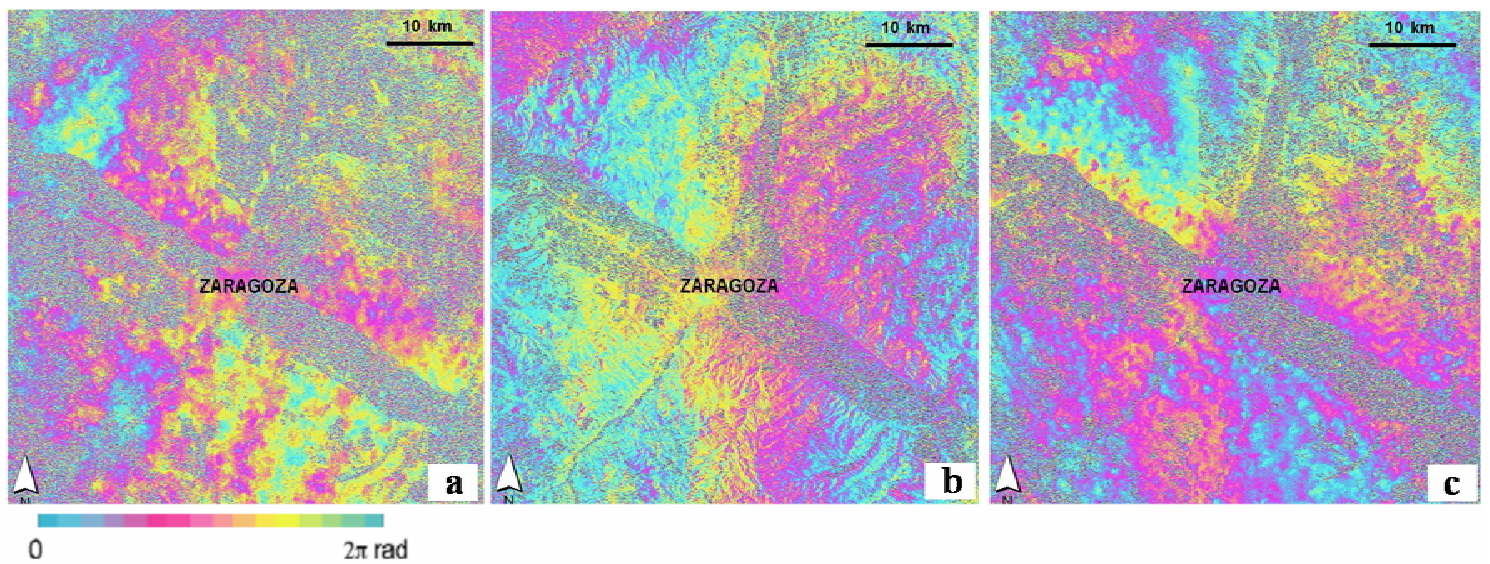

882

883

Figure 5

\begin{tabular}{r|rrr}
\multicolumn{3}{c}{ Number of weather stations } \\
26-abr-1995 \\
05-jul-1995
\end{tabular}

885

886 Figure 6

887 

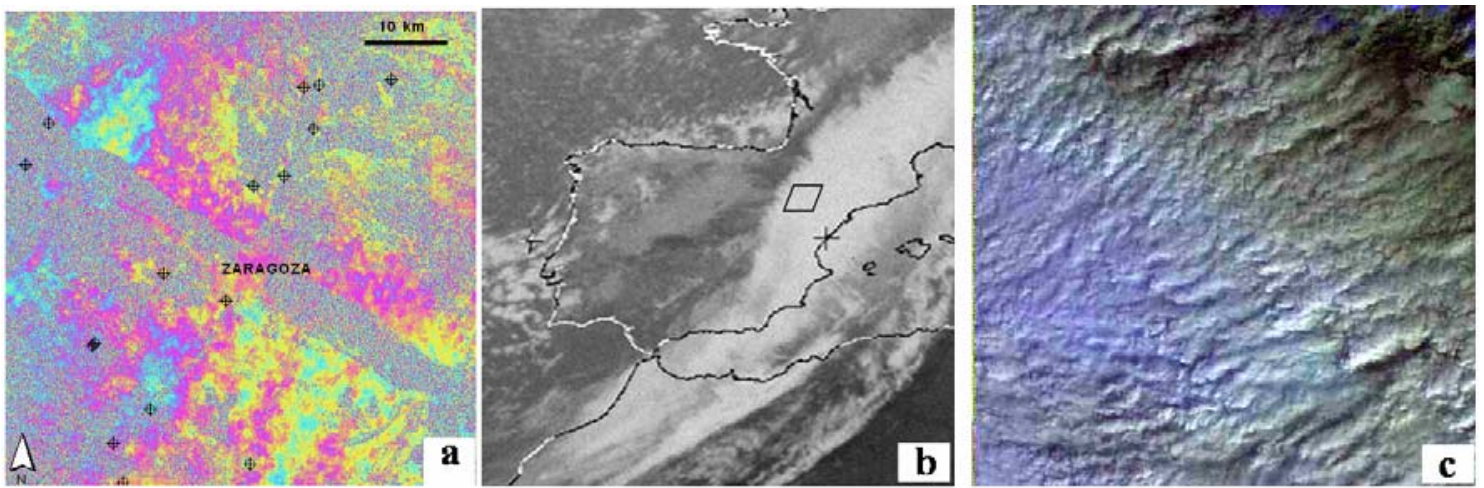

$889 \quad$ Figure 7

890

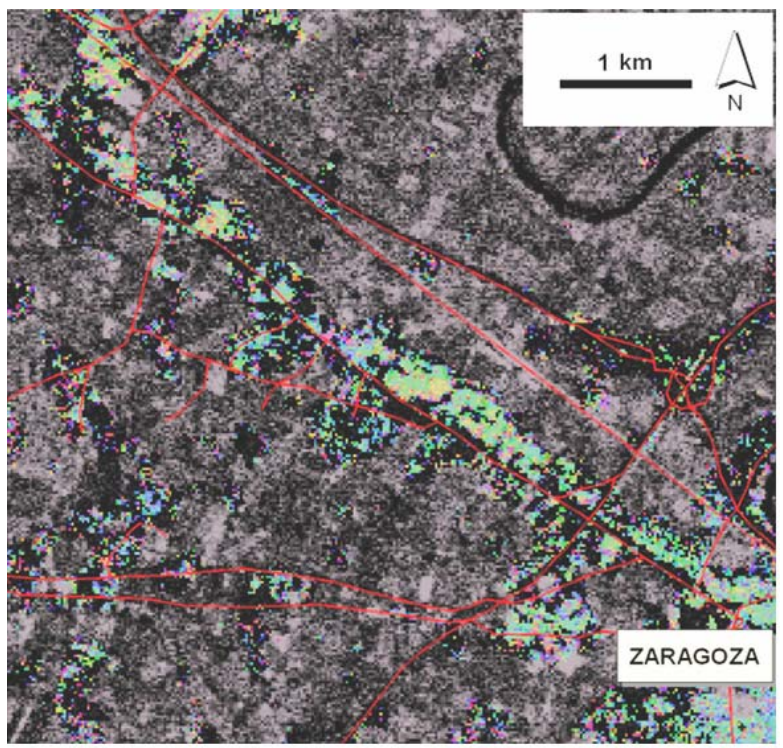

891

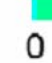

$2 \pi \mathrm{rad}$

$892 \quad$ Figure 8

893
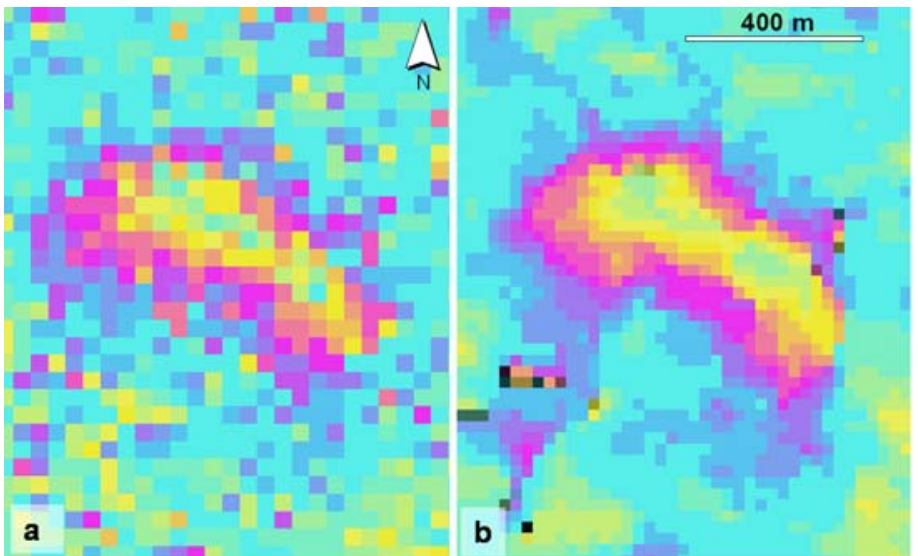

895

Figure 9

896 

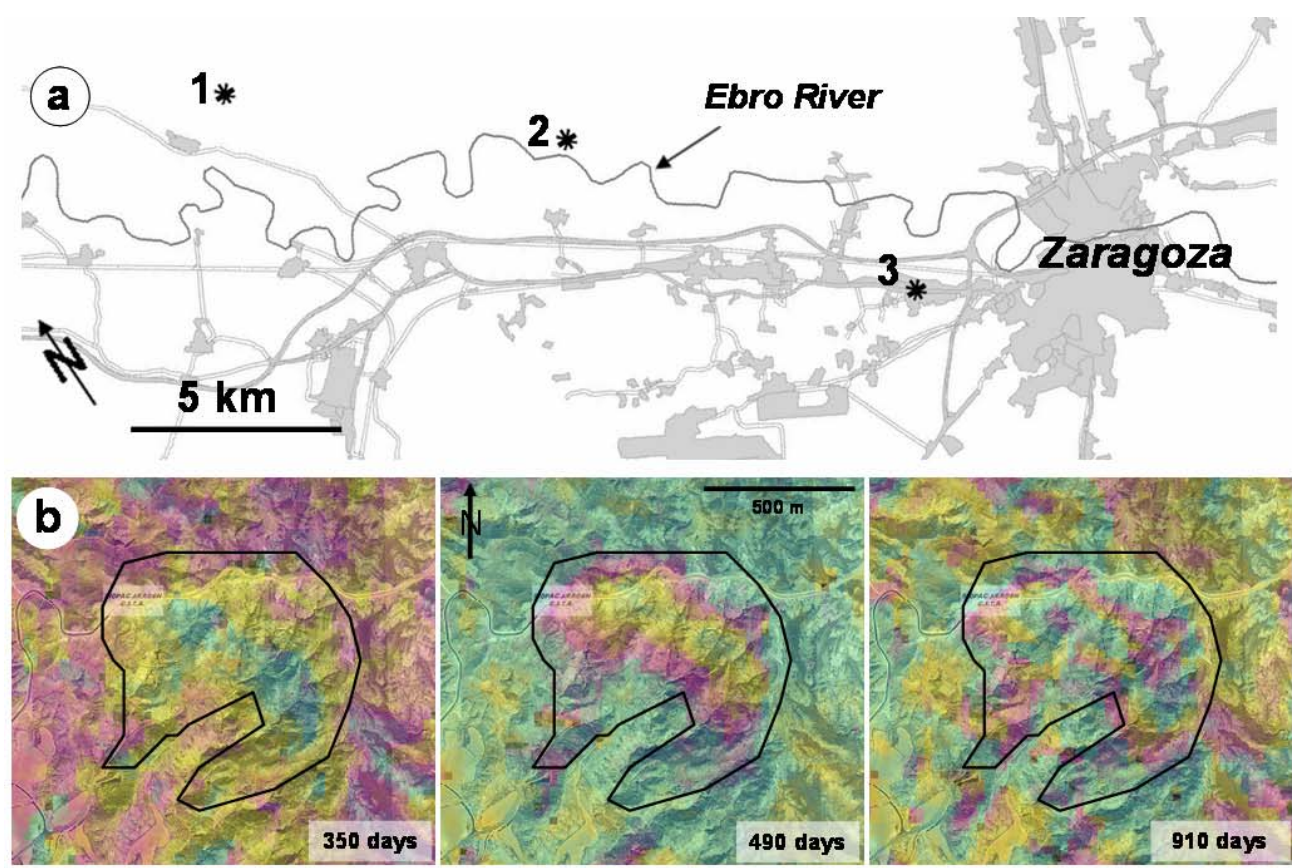

897
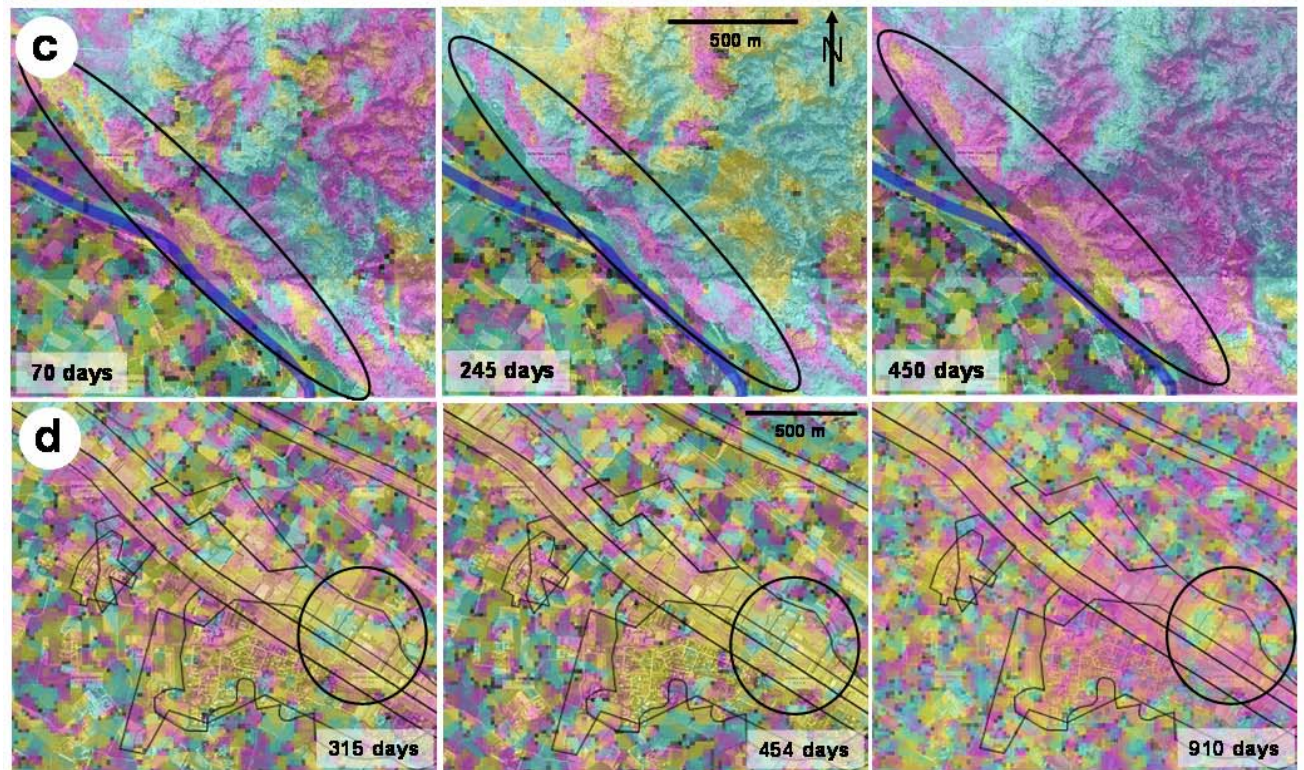

898 Figure 10 